\title{
Evaluating of Salt Stress Tolerance in Selected Wheat Mutant Progenies with Contributing Expression Analysis of TaWRKY Genes and Antioxidant Defence Parameters
}

\author{
Ayşe Şen ${ }^{1 *}$, Fatma Sarsu² \\ ${ }^{1}$ Department of Biology, Faculty of Science, Istanbul University, 34134, Vezneciler, Istanbul, Turkey. \\ ${ }^{2}$ Plant Breeding and Genetics Section, Joint FAO/IAEA Division, Vienna International Centre, PO Box 100, A- \\ 1400 Vienna, Austria. \\ *senayse@istanbul.edu.tr
}

Received: 4 June 2018

Accepted: 24 September 2018

DOI: $10.18466 /$ cbayarfbe. 430620

\begin{abstract}
In current work, the seeds from two candidate fifth-generation moderately salt tolerant wheat mutant progenies (Triticum aestivum L. cv. Adana 99) developed with using sodium azide (as a mutagenic agent) and from their parent (commercial cultivar) were sown in the growth chamber to evaluate their performance under control and $150 \mathrm{mM} \mathrm{NaCl}$ treatment conditions. Compared with commercial cultivar, mutants demonstrated much higher activities of superoxide dismutase, catalase and guaiacol peroxidase, and chlorophyll contents, and much lower contents of lipid peroxidation and values of electrolyte leakage under control condition. On the other hand, contents of lipid peroxidation and value of electrolyte leakage increased, but chlorophyll content decreased more severely in commercial cultivar than mutants under salt stress condition. In addition to increasing in expression levels of TaWRKY5, TaWRKY10 and TaWRKY44 genes in mutants positively regulated in salt stress responses by either direct or indirect activation of the cellular antioxidant enzyme responses or activation of stress-related gene expression. These candidate salt tolerant wheat mutant progenies will be used to increase the salt tolerance in the wheat-breeding programmers.
\end{abstract}

Keywords: Antioxidant enzymes, salt stress tolerance, sodium azide mutagenesis, wheat, qPCR, WRKY transcription factors.

\section{Introduction}

Soil salinity is one of the major environmental stresses affecting plant growth and productivity owing to irrigation with saline water, rising water tables resulting from land clearing or natural subsoil salinity. Excessive amount of soluble salts in soil induces water deficit by decreasing the osmotic potential of soil solutes thus making it difficult or roots to extract water from their surrounding media [1]. Wheat (Triticum aestivum L.) constitutes among the world's major staple food crop, but production and productivity of wheat inhibit by salt stress. Although temporary solutions have reduced the negative impact of salinity on plants implementing these solutions are not always easy [2]. Thus, one of the most effective solutions is to develop salt-tolerant novel cultivars. Induced mutations are the tools for producing novel genome arrangement for genetic improvement of agricultural crops. Chemical mutagens, like sodium azide $\left(\mathrm{NaN}_{3}\right)$, frequently used for this purpose and generally lead to create base pair mutations especially GC:AT (guanine:cytosine to adenine:tymine) resulting in amino acid changes, which change the function of proteins. Thus, they induce a wide range variation of morphological and yield structure parameters in comparison to normal plants, and become important tool to enhance agronomic traits of crop plants. The role of induced mutations in increasing the genetic variability for agronomic traits in various crop plants have been reported by a number of scientists [3].

Mechanisms of stress tolerance in plant regulate by several components. On the molecular level, the induction of stress-associated transcription factors (TFs) is one the key components of signal transduction pathway. The WRKY transcription factor belongs to a very large family of transcription factors potentially involved in various developmental and physiological metabolism, including disease resistance, senescence, growth and developmental processes, as well as biotic and abiotic responses. It has over 90 members in wheat. Over-expression of these WRKYs resulted in increased either biotic or abiotic stress tolerance [4-7]. Recently scientists showed that transgenic plants over-expressing TdWRKY5 [4], TaWRKY10 [5], TaWRKY44 [6] and 
TaWRKY93 [7] genes have demonstrated improved multiple abiotic stress tolerance when compared to wild-type plants. On the other hand, maize WRKY transcription factor $Z m W R K Y 17$ negatively regulates salt stress tolerance in transgenic Arabidopsis plants [8].

Another strategy for plants to cope with stress tolerance is to control the production of reactive oxygen species (ROS). ROS are toxic molecules found in various subcellular compartments. The equilibrium between the production and detoxification of ROS are sustained by enzymatic and non-enzymatic antioxidants. The enzymatic antioxidant system is one of the protective mechanisms including superoxide dismutase (SOD: EC 1.15.1.1), which can be found in various cell compartments and it catalyzes the disproportion of two $\mathrm{O}_{2} \cdot{ }^{\cdot-}$ radicals to $\mathrm{H}_{2} \mathrm{O}_{2}$ and $\mathrm{O}_{2} \cdot \mathrm{H}_{2} \mathrm{O}_{2}$ is eliminated by various antioxidant enzymes such as catalases (CAT: EC 1.11.1.6) and peroxidases (POX: EC 1.11.1.7), which convert $\mathrm{H}_{2} \mathrm{O}_{2}$ to water [9]. Sajid and Aftab [10] reported that SOD, POX and CAT activities were increased under saline environment in in vitro selected salt tolerant potato lines than control.

In this context, the purpose of the study was to evaluate the performances of two candidate moderately salt tolerant fifth-generation wheat mutant progenies, developed using $\mathrm{NaN}_{3}$, as a mutagenic agent, performance under saline conditions by measuring the activities of SOD, CAT and POX, the contents of chlorophyll andlipid peroxidation, and the expression analysis of TaWRKY5, TaWRKY10 andTaWRKY44 genes.

\section{Materials and Methods \\ 2.1. Materials}

Utilized bread wheat cultivar Adana 99 (Triticum aestivum L. cv.) was obtained from the Eastern Mediterranean Agricultural Institute in Adana, Turkey. Used mutant lines in this study were obtained with 4 $\mathrm{mM} \mathrm{NaN} \mathrm{N}_{3}$ treatment under in vitro condition. Treated and non-treated embryonic calli were screened for salinity tolerance by putting $125 \mathrm{mM} \mathrm{NaCl}$ in indirect regeneration media. Then, the mutant lines were segregated up to fifth generation by combining in vitro and in vivo $\mathrm{NaCl}$ screening techniques. Both treatment concentrations, which were given in here, either $\mathrm{NaN}_{3}$ or $\mathrm{NaCl}$ were determined according to the results of preliminary experiments (unpublished data by Sen and Sarsu).

\subsection{Methods}

\subsubsection{Growth and stress treatments of materials}

Seeds from commercial cultivar and mutant progenies were sown to pots filled with a soil mixture containing perlite and peat moss at the ratio $2: 1(\mathrm{v} / \mathrm{v})$. The pots were kept in a growth chamber for 16 hours light / 8 hours dark photoperiod, irradiance of $500 \mu \mathrm{mol} \mathrm{m} \mathrm{m}^{-2} \mathrm{~s}^{-1}$ photon flux density, and at a temperature of $26^{\circ} \mathrm{C}$ for 28 days. After the two weeks germinating period, 14-dayold seedlings were irrigated with $1 / 10$ Hoagland Solution containing $150 \mathrm{mM} \mathrm{NaCl}$ for 2 weeks with a three-day interval. All biochemical analysis and measuring the transcription levels of the target genes were done using leaves of fifth generation mutants and their parent (as a control). For qPCR analysis, plants were harvested at 0 and $2 \mathrm{~h}$ of treatment. For other analysis, plants were harvested $28^{\text {th }}$ day of treatment. Leaf samples were frozen in liquid nitrogen, and then stored at $-80^{\circ} \mathrm{C}$ until RNA extraction.

2.2.2. Measurement of chlorophyll and the end products of lipid peroxidation contents, and electrolyte leakage as bio-indicators for stress damage

Chlorophyll content was measured by spectrophotometry, following the method of Arnon [11] and the end products of lipid peroxidation was measured as the amount of thiobarbituric acid-reactive substances (TBARS) determined by the thiobarbituric acid (TBA) reaction as described by Heath and Packer [12]. Electrolyte leakage was examined as described by Song et al. [13].

\subsubsection{Measurement of antioxidant enzyme activities as bio-indicators for stress response}

To measure antioxidant enzymes, $200 \mathrm{mg}$ of frozen leaf tissue were extracted with using extraction buffer containing $100 \mathrm{mM}$ phosphate buffer ( $\mathrm{pH} \mathrm{7.0),1 \%}$ PVP40 (w/v) and $0.1 \mathrm{mM}$ Na-EDTA. Samples were centrifuged at $13,000 \mathrm{xg}$ for 25 minutes at a $4{ }^{\circ} \mathrm{C}$, supernatant was used for further analysis. Protein content was measured according to Bradford [14]. SOD was assayed by monitoring the superoxide radicalinduced nitro blue tetrazolium chloride (NBT) reduction at $560 \mathrm{~nm}$ [15]. One unit of SOD activity was characterized as the amount of enzyme, which leads to a $50 \%$ inhibition of the photochemical reduction of NBT. The measurement of POX activity was measured at 470 $\mathrm{nm}$ by using $\mathrm{H}_{2} \mathrm{O}_{2}$ and guaiacol as substrates. The disappearance of $\mathrm{H}_{2} \mathrm{O}_{2}$ was monitored at $240 \mathrm{~nm}$ for determination of CAT activity [16].

\subsection{4. qPCR analysis}

The specific primers for TaWRKY genes (Table 1) were designed using web-based tool Primer 3 (http://bioinfo.ut.ee/primer3-0.4.0/). To design primers, mRNA sequences from target genes were downloaded from GenBank of NCBI (National Center for Biotechnology Information), selected and loaded on Primer3 and run the default parameters for melting temperatures ranged between $60^{\circ}$ and $65^{\circ} \mathrm{C}$, the primer and DNA fragment lengths were arranged 18-24 bp, 300-400 bp, respectively. 
RNA was isolated from frozen leaf by TRIzol reagent. Subsequently the cDNA was synthesized via the Superscript II reverse transcriptase according to the manufacturer's instructions. The qPCR was performed on a Rotor Gene Q Real- Time PCR cycler (Qiagen,
USA). TaActin gene was used as an internal control. The relative gene expression was calculated using the $2^{-}$ $\Delta \Delta \mathrm{CT}$ equation [6].

Table 1. Designed probes for detection of expression level of WRKY genes in wheat genome.

\begin{tabular}{|c|c|c|c|}
\hline Genes & $\begin{array}{l}\text { GenBank } \\
\text { Accession No }\end{array}$ & $\begin{array}{l}\text { Amplicon } \\
\text { Sizes (bp) }\end{array}$ & Primers \\
\hline TaWRKY44 & KR827395.1 & 382 & $\begin{array}{l}\text { F: 5'-CCGTGGATAAACCTGCTGAT-3' } \\
\text { R: 5'-CACTTGAGCCAGACGATTGA-3' }\end{array}$ \\
\hline TaWRKY 10 & EF368361.1 & 375 & $\begin{array}{l}\text { F: 5'-CTCCGACTACTCGCTGCTTC-3' } \\
\text { R: 5'-AGGTGGTGAGGACGTAGTGC-3' }\end{array}$ \\
\hline TaWRKY5 & EU665434.1 & 323 & $\begin{array}{l}\text { F: 5'-CCCGAGCAGATAGAGATGGA-3' } \\
\text { R: 5'-CCGACGTCTTCCTCTTCTTG-3' }\end{array}$ \\
\hline
\end{tabular}

\subsubsection{Data analyses}

One-way analysis of variance (ANOVA) was used to make statistical interpretations for spectrophotometric assay. Their means were compared with the LSD test [17]. The results of gene expression analysis are expressed as the mean values \pm standard deviation of three replicates.

\section{Results and Discussion}

Salinity is one of the major environmental factors that significantly limit the production of agricultural crops worldwide. Even if the wheat crop is known to be a moderately salt tolerant, the varietal differences in salinity tolerance exist among the genotypes [18]. Thus, it is critical important to determine the salt susceptibility of agricultural crops, which are often cultivated by farmers, and to develop improved novel cultivars with salt tolerance for sustainable crop production in salt affected area. Different strategies exist for this purpose. Induced mutations by artificial way, namely, using mutagenic agent like $\mathrm{NaN}_{3}$ is one of the ways to create new genetic arrangements on the plant genomes. Mutation is a heritable change in genes and chromosomes, and occurs at random, either spontaneous or induced with mutagenic agents. Chemical mutagens have the ability to induce resistance/tolerance to multiple stresses in plant and generating crops having multi-stress resistance/tolerance capability [3]. In the presented study, we characterized the salt tolerance levels in two candidate salt tolerant mutant progenies induced with $4 \mathrm{mM} \mathrm{NaN}$ application derived from Adana 99 spring wheat cultivar using stress-derived damage, stress-derived defense and stress-derived signaling parameters.
3.1. Measurement of chlorophyll and TBARS contents, and electrolyte leakage as indicators forstress-derived damage

Electrolyte leakage and the end products of lipid peroxidation are indicators of stress-derived cell damage on bio-membrane due to the oxidative attack. Table 2 shows parameters related to stress damage in 4-weekold seedlings under control and stress treatments in this study. As seen in the table, TBARS content and electrolyte leakage were measured lower, whereas chlorophyll contents was measured higher in mutants than in parental lines under control condition. Due to $150 \mathrm{mM} \mathrm{NaCl}$ treatments, the values of TBARS and electrolyte leakage were increased in parent and mutant progenies than control conditions, whereas decreases were measured in chlorophyll content. All observed increases and decreases under salt stress treatments were lower in mutants than parental line. For example, the increase in TBARS content in the parental line was detected as $122.89 \%$ under stress treatment than control condition; this value was measured in mutants as a $86.93 \%$ and as a $89.14 \%$, respectively. The electrolyte leakage $(\%)$ changes in parental and mutant lines were similar to the TBARS values. Like us, the low value of electrolyte leakage and TRARS contents are important signs of the oxidative-damage-limiting capacity under salinity as reported in salt tolerant rice mutants [13]. A decrease in the content of chlorophyll is another phenomenon under salt stress conditions [13]. In this study, mutant lines showed lower chlorophyll content decreases under salt stress treatment than parental line. These decreases were measured as a $69.93 \%$ in the parental line, and as a $75.21 \%$ in the Mutant 1 and as a $73.99 \%$ in the Mutant 2. 
Table 2. Parameters related to stress damage in parental line and mutants under control and stress treatment conditions.

\begin{tabular}{lcccccc}
\hline Parameters & \multicolumn{3}{c}{ Control } & \multicolumn{3}{c}{ 150 mMNaCl } \\
\cline { 2 - 6 } & Parent & Mutant 1 & Mutant 2 & Parent & Mutant 1 & Mutant 2 \\
\hline $\begin{array}{l}\text { TBARS Content } \\
\left(\mathrm{nmol}(\mathrm{g} \mathrm{FW})^{-1}\right)\end{array}$ & $2.49^{\mathbf{a}^{*}}$ & $1.76^{\mathbf{b}}$ & $1.75^{\mathbf{b}}$ & $5.55^{\mathbf{c}}$ & $3.29^{\mathbf{d}}$ & $3.31^{\mathbf{d}}$ \\
$\begin{array}{l}\text { Chlorophyll Content } \\
\left(\mathrm{mg}(\mathrm{g} \mathrm{FW})^{-1}\right)\end{array}$ & $1.03^{\mathbf{a}^{*}}$ & $1.21^{\mathbf{b}}$ & $1.19^{\mathbf{b}}$ & $0.71^{\mathbf{c}}$ & $0.91^{\mathbf{d}}$ & $0.88^{\mathbf{d}}$ \\
$\begin{array}{l}\text { Electrolyte Leakage } \\
(\%)\end{array}$ & $8^{\mathbf{a}^{*}}$ & $7.2^{\mathbf{b}}$ & $7.6^{\mathbf{b}}$ & $27.2^{\mathbf{c}}$ & $17.6^{\mathbf{d}}$ & $16.4^{\mathbf{d}}$ \\
\hline
\end{tabular}

*Significant difference at $\mathrm{P}<0.05,(\mathrm{n}=5)$.

\subsection{Antioxidant enzyme activities as indicators for stress-derived defense}

Salt stress induced the production of reactive oxygen species, such as ${ }^{\circ} \mathrm{OH}, \mathrm{O}_{2}{ }^{-}$, and $\mathrm{H}_{2} \mathrm{O}_{2}$ in chloroplasts, mitochondria, and peroxisomes. Consequently, the activation of complex metabolic activity including antioxidative pathways is a common adaptive mechanism used by plants to cope with oxidative stress $[9,10]$. In order to evaluate the contribution of the inductive responses of antioxidant enzymes in tolerance to salt stress, we measured the activity of SOD, CAT and POX in salt tolerant mutants and their parent. Before the salt stress treatment, the activities in these enzymes were detected higher in mutants than their parent. However, under stress treatment, the activities of SOD, CAT and POX were lower increased in mutants than their parent (Table 3). For example, CAT activity in parent was detected as $92.2 \%$ depending on the 150 $\mathrm{mM} \mathrm{NaCl}$ treatment than control condition; this value was measured in mutants as a $71.32 \%$ and as a $73.03 \%$, respectively. It is thought that higher measured antioxidant activity in the mutant progenies compared to the parent under control condition may be the reason to lower measured electrolyte leakage and TBARS content in the mutants than their parent under $150 \mathrm{mM} \mathrm{NaCl}$ treatment. Like us, advanced antioxidant responses were measured in in EMS-derived salt-tolerant Chrysanthemum mutants by Hossain et al. [19] and in pingyangmycin-derived drought- tolerant peanut mutants by Sui et al. [20].

Table 3. Parameters related to stress response in parental line and mutants under control and stress treatment conditions.

\begin{tabular}{|c|c|c|c|c|c|c|}
\hline \multirow{2}{*}{ Parameters } & \multicolumn{3}{|c|}{ Control } & \multicolumn{3}{|c|}{$150 \mathrm{mMNaCl}$} \\
\hline & Parent & Mutant 1 & Mutant 2 & Parent & Mutant 1 & Mutant 2 \\
\hline $\begin{array}{l}\text { SOD Activity } \\
\left(\mathrm{U}(\mathrm{mg} \text { protein })^{-1}\right)\end{array}$ & $18.71^{\mathrm{a}^{*}}$ & $22.53^{\mathbf{b}}$ & $21.21^{\mathbf{b}}$ & $38.39^{c}$ & $41.95^{\mathrm{cd}}$ & $42.89^{d}$ \\
\hline $\begin{array}{l}\text { CAT Activity } \\
\left(\mathrm{U}(\mathrm{mg} \text { protein })^{-1}\right)\end{array}$ & $2.05^{\mathrm{a}^{*}}$ & $2.58^{\mathbf{b}}$ & $2.67^{\mathbf{b}}$ & $3.94^{\mathrm{c}}$ & $4.42^{d}$ & $4.62^{d}$ \\
\hline $\begin{array}{l}\text { POX Activity } \\
\left(\Delta \mathrm{A}_{470}(\mathrm{mg} \text { protein })^{-1}\right)\end{array}$ & $29.67^{a^{*}}$ & $36.21^{b}$ & $39.29^{b}$ & $69.64^{c}$ & $80.42^{d}$ & $81.07^{\mathrm{d}}$ \\
\hline
\end{tabular}

*Significant difference at $\mathrm{P}<0.05,(\mathrm{n}=5)$.

\subsection{Gene expression analysis as indicators for stress- derived signaling}

The adaptive response to salt stress is a dynamic regulation process. Many functional proteins like WRKY transcriptional factors are implicated in this pathway. In our study, we measured the expression levels of TaWRKY5, TaWRKY10 and TaWRKY44 genes, which were detected to involve in salt tolerance in transgenic plants [4-6]. The relative expression values of TaWRKY genes in mutants were higher than their parent. The average increase in expression levels of TaWRKY5, TaWRKY10 and TaWRKY44 genes in 2-week-old seedlings at the second hour of
$150 \mathrm{mM} \mathrm{NaCl}$ application were measured as a 2.08-, 2.33- and 2.72-fold higher in mutants than their parent, respectively (Figure 1).

\section{Conclusion}

Based on these data, we concluded that the increase salt tolerance level in advanced mutant progenies demonstrated with enhancing the expression level of TaWRKY5, TaWRKY10 and TaWRKY44 genes, higher activity of ROS-scavenging enzymes, including SOD, CAT and POX, and lower increases in contents of electrolyte leakage and TBARS. However, further evidence are needed to clarify the activities of these enzymes are directly regulates of TaWRKY5, 


\section{TaWRKY10 and TaWRKY44 genes.}
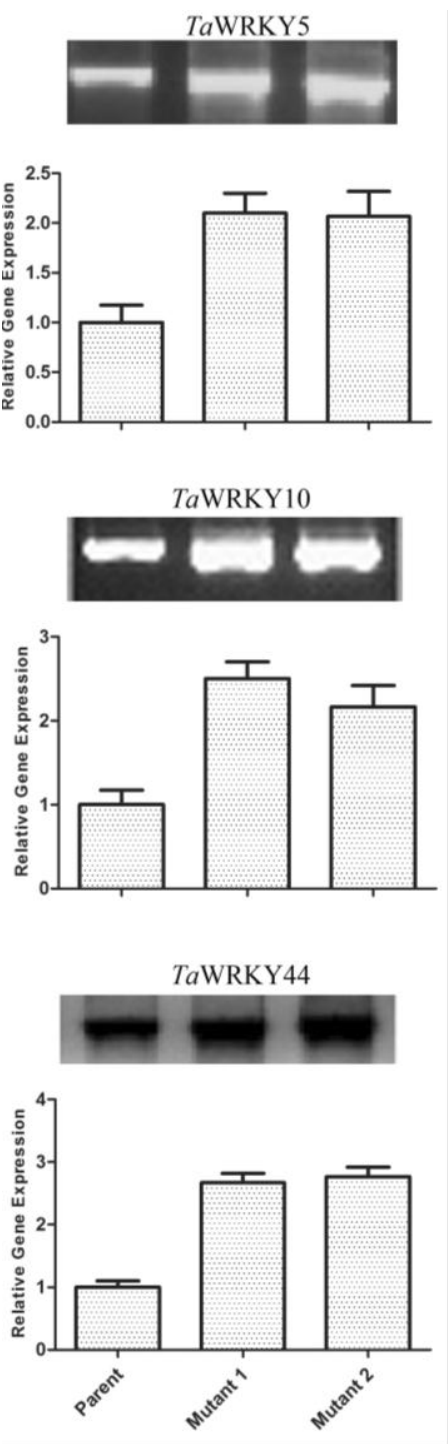

Figure 1. qPCR results from expression of TaWRKY5, TaWRKY10 and TaWRKY44 in leaf of parent and mutant progenies treated with150 $\mathrm{mMNaCl}$. Expression was normalized using TaActin gene. Non-treated parent was used a reference point.

\section{Acknowledgements}

AS planned and performed experimental design and data analysis, and participated in drafting the manuscript. FS planned experimental design and provided wheat cultivar used in this study and participated in drafting the manuscript. This studywas supported by The Research Fund of Istanbul University by Project Numbers: BEK-2017-24939, 45260 and 49463 to AS. Authors read and approved the final manuscript.

\section{Conflict of interest}

The authors declare that they have no conflict of interest.

\section{References}

1. Rengasamy, R, Soil processes affecting crop production in saltaffected soils. Functional Plant Biology, 2010, 37, 613-620.

2. Rana, V, Ram, S, Sendhil, R, Nehra, K.M, Sharma, I, Physiological, biochemical and morphological study in wheat (Triticum aestivum L.) RILs population for salinity tolerance. Journal of Agricultural Science, 2015, 7, 119-128.

3. Mostafa, G.G, Effect of sodium azide on the growth and variability induction in Helianthus annuus L. International Journal of Plant Breeding and Genetic, 2011, 5, 76-85.

4. Yousfi, F-E, Makhloufi, E, Marande, W, Ghorbel, A.W, Bouzayen, M, Berges, H, Comparative analysis of WRKY genes potentially involved in salt stress responses in Triticum turgidum L. ssp. Durum. Frontiers in Plant Science, 2017, 7, 2034.

5. Wang, C, Deng, $\mathrm{P}$, Chen, L, Wang, $\mathrm{X}, \mathrm{Ma}, \mathrm{H}, \mathrm{Hu}, \mathrm{W}$, Yao, N, Feng, Y, Chai, R, Yang, G, He, G, A wheat WRKY transcriptional factor TaWRKY10 confers tolerance to multiple abiotic stresses in transgenic tobacco. PlosOne, 2013, 8(6):e65120.

6. Wang, X, Zeng, J, Li, Y, Rong, X, Sun, J, Sun, T, Li, M, Wang, L, Feng, Y, Chai, R, Chen, M, Chang, J, Li, K, Yang, G, He, G, Expression of TaWRKY44, a wheat WRKY gene, in transgenic tobacco confers multiple abiotic stress tolerances. Frontiers in Plant Science, 2015, 6, 615.

7. Qin, Y, Tian, Y, Liu, X, A wheat salinity-induced WRKY transcription factor TaWRKY93 confers multiple abiotic stress tolerance in Arabidopsis thaliana. Biochemical and Biophysical Research Communications, 2015, 464, 428-433.

8. Cai, R, Dai, W, Zhang, C, Wang, Y, Wu, M, Zhao, Y, Ma, Q, Xiang, Y, Cheng, B, He maize WRKY transcription factor ZmWRKY17 negatively regulates salt stress tolerance in transgenic Arabidopsis plants. Planta, 2017, 246, 1215-1231.

9. Rai, M.K, Kalia, R.K, Singh, R, Gangola, M.P, Dhawan, A.K, Developing stress tolerant plants through in vitro selection-an overview of the recent progress. Environmental and Experimental Botany, 2011, 71, 89-98.

10. Sajid, Z.A, Aftab, F, Plant regeneration from in vitro-selected salt tolerant callus cultures of Solanum tuberosum L. Pakistan Journal of Botany, 2014, 46, 1507-1514.

11. Arnon, D.I, Copper enzymes in isolated chloroplasts. Polyphenoloxidase in Beta vulgaris. Plant Physiology, 1949, 24, $1-15$.

12. Heath, R.L, Packer, L, Photoperoxidation in isolated chloroplasts. I. Kinetics and stoichiometry of fatty acid peroxidation, Archives of Biochemistry and Biophysics, 1968, 125, 189-198.

13. Song, J.Y, Kim, D.S, Lee, M-C, Lee, K.J, Kim, J-B, Kim, S.H, Ha, B-K, Yun, S.J, Kang, S-Y, Physiological characterization of gamma-ray induced salt tolerant rice mutants. Australian Journal of Crop Science, 2012, 6(3), 421-429.

14. Bradford, M.M, A rapid and sensitive method for the quantitation of microgram quantities of protein utilizing the principle of protein-dye binding. Analytical Biochemistry, 1976, 72, 248-254.

15. Dhindsa, R.S, Plumb-Dhindsa, P, Thorpe, T.A, Leaf senescence correlated with increased levels of membrane permeability and lipid peroxidation and decreased levels of superoxide dismutase and catalase. Journal of Experimental Botany, 1981, 32, 93-10. 
16. Aebi, H, Catalase in vitro. Methods Enzymology, 1984, 105, 121 126.

17. Zar, J.H, Biostatistical Analysis, Prentice-Hall Inc., Englewood Cliffs, Jersey, 1984.

18. Goudarzi, M, Pakniyat, $H$, Evaluation of wheat cultivars under salinity stress based on some agronomic and physiological traits. Journal of Agriculture and Social Science, 2008, 4, 81-84.

19. Hossain, Z, Mandal, A.K.A, Datta, S.K, Biswas, A.K, Development of $\mathrm{NaCl}$ tolerant strain in Chrysanthemum morifolium Ramat. throughin vitro mutagenesis. Plant Biology, 2006, 8, 450-461.

20. Sui, J, Wang, Y, Wang, P, Qiao, L, Sun, S, Hu, X, Chen, J, Wang, $\mathrm{J}$, Generation of peanut drought tolerant plants by pingyangmycin- mediated in vitro mutagenesis and hydroxyproline-resistance screening. PLoSOne, 2015, 10:e0119240. 